\title{
In-vivo and in-vitro determination of components of rabbit early pregnancy factors*
}

\author{
K. Sueoka, A. M. Dharmarajan, T. Miyazaki, S. J. Atlas and E. E. Wallach \\ The Johns Hopkins University, School of Medicine, Department of Gynecology and Obstetrics, \\ 600 N. Wolfe Street, Baltimore, Maryland 21205, USA
}

\begin{abstract}
Summary. Two types of rabbit early pregnancy factor (EPF) components, prepared from the in-vitro perfused ovary and oviduct and from serum ammonium sulphate fractions, were investigated to elucidate the source of EPF production. The state of the animals, i.e. pregnant, pseudopregnant, unstimulated or platelet activating factor (PAF)-treated, and order of addition of the components to the assay lymphocytes were varied to characterize conditions of production and expression of EPF activity. Although each component alone had no EPF activity, combination of two components, i.e. ovary and oviduct components, or serum precipitate and supernatant components, expressed EPF activity. The oviduct and serum supernatant components were produced in pregnancy and pseudopregnancy but the ovary and serum precipitate components were produced only in pregnancy. The similarity of the production pattern and ability of the perfusate and serum components to yield EPF activity when combined suggests that they are similar or the same. The sources of stimulation of EPF production did not appear to affect component production because the activity produced by the perfused ovary and oviduct in pregnancy or in response to PAF stimulation appeared similar. Oviduct and supernatant components apparently bound directly to lymphocytes. These results suggest that EPF components are produced in the ovary and oviduct individually and that the combination of the two components expresses EPF activity in the rabbit.
\end{abstract}

Keywords: EPF; component; ovary; oviduct; serum; rabbit

\section{Introduction}

Early pregnancy factor (EPF) is a glycoprotein found in the serum and urine of mammalian species very early in pregnancy (Morton et al., 1976; Rolfe et al., 1983). The in-vitro perfused rabbit ovary and oviduct produces EPF as early as $3 \mathrm{~h}$ after fertilization (Sueoka et al., 1988a). It is possible that EPF production is triggered by factors released by the early embryo including 'ovum factor' (Cavanagh et al., 1982; Sueoka et al., 1988a) and embryo-derived platelet-activating factor (Orozco et al., 1986; Sueoka et al., 1988b), detected during the preimplantation period (O'Neill, 1985; O'Neill et al., 1985). Exposure of the in-vitro perfused ovary and oviduct to platelet-activating factor (PAF) results in production of EPF-like activity (Sueoka et al., 1988b). The previous study, using an in-vitro organ culture system, suggested that the two components were produced in ovary and oviduct (Morton et al., 1980). Our perfusion experiments demonstrated more directly that the perfusate of both organs or the combination of individual perfusates contain EPF activity whereas neither ovary nor oviduct alone produces EPF-like activity (Sueoka et al., 1988a). Similarly, the serum of pregnant animals has yielded two separate EPF components: EPF-A and EPF-B by ammonium sulphate fractionation (Morton et al., 1980; Clarke et al., 1980).

\footnotetext{
*Reprint requests to: E. E. Wallach, M.D.
} 
The objective of this study was to determine the source of rabbit EPF components and characterize conditions of production and expression of EPF activity.

\section{Materials and Methods}

Animals. Sexually mature virgin New Zealand White rabbits weighing 3.5-4.5 kg were used in all experiments. Female rabbits were isolated for a minimum of 3 weeks before the experimental procedure. The rabbits were caged individually under controlled temperature and light with free access to Purina Rabbit Chow and water. Three sets of rabbits were prepared for experiments: (1) pregnant ( $24 \mathrm{~h}$ after mating); (2) pseudopregnant ( $24 \mathrm{~h}$ after the injection of human chorionic gonadotrophin (hCG: 100 i.u., Pregnyl: Organon, West Orange, NJ, USA) and (3) unstimulated intact rabbits. Pregnancy and pseudopregnancy were confirmed by microscopic examination of ova collected from the oviduct (phase-contrast, $\times 40$ objective). The ovaries and oviducts of the intact rabbits were examined to confirm that ovulation had not occurred.

In-vitro perfusion. Rabbits were anaesthetized with pentobarbitone sodium $(32 \mathrm{mg} / \mathrm{kg})$, given heparin sulphate (120 U/kg; Invenex Laboratories, Chagrin Falls, OH, USA) for anticoagulation, and then subjected to laparotomy. Three different types of perfusion procedures were carried out ( 7 perfusions for each procedure) to determine the source of PAF-induced EPF activity: (A) ovary + oviduct; (B) ovary alone; and (C) oviduct alone. For all types of perfusions, collateral vessels and the utero-tubal junction were ligated and each ovarian artery and vein was individually cannulated in situ. The ovary with its vascular pedicle and attached oviduct was removed and placed in a perfusion chamber for the ovary + oviduct perfusion. For perfusion of the ovary alone only the cannulated ovary with its pedicle was removed and perfused. Perfusion of the oviduct alone required cannulation as usual and then ligation of the ovarian artery and vein distal to the bifurcation of the branches to the oviduct. Both ovary and oviduct were then removed and placed in the perfusion system (i.e. ovary was present, but not perfused). The perfusion medium consisted of $150 \mathrm{ml}$ tissue culture Medium 199 (Whittaker M.A. Bioproducts, Walkerville, MD, USA) supplemented with heparin sulphate (200 U/l), insulin (20 U/l; Squibb-Nova, Inc., Princeton, NJ, USA), streptomycin $(50 \mathrm{mg} / 1$; Sigma Chemical Co., St Louis, MO, USA), and penicillin G $(75 \mathrm{mg} / 1$; Sigma), adjusted to a pH of 7.4. The flow rate was maintained at $1.5 \mathrm{ml} / \mathrm{min}$. The arterial cannulation procedure and perfusion apparatus have been previously described in detail (Lambertsen et al., 1976; Kobayashi et al., 1981). The vein cannulation and the procedure for perfusion of the ovary plus oviduct were as described by Dharmarajan et al. (1988) and by Sueoka et al. (1988a), respectively. Perfusate samples collected from the cannulated vein at $120 \mathrm{~min}$ after the onset of perfusion were used for EPF assay. The perfusion procedure was carried out in a constant-temperature room at $37^{\circ} \mathrm{C}$ for $5 \mathrm{~h}$.

Separation of serum components. Blood was collected from the inferior vena cava at the time of laparotomy from pregnant, pseudopregnant and unstimulated rabbits ( 3 for each stage). Serum was assayed for EPF after inactivation at $56^{\circ} \mathrm{C}$ for $30 \mathrm{~min}$ and used for fractionation of serum components as previously described for pig (Clarke et al., 1980) and mouse (Morton et al., 1980; Cavanagh et al., 1982). Ammonium sulphate was added to the serum to give $40 \%$ saturation. After incubating for $15 \mathrm{~min}$ on ice, the precipitate was collected by centrifugation at $400 \mathrm{~g}$ for $20 \mathrm{~min}$ at $4^{\circ} \mathrm{C}$. The precipitate was dissolved in $0.05 \mathrm{M}-\mathrm{Tris}-\mathrm{HCl}, 0.1 \mathrm{M}-\mathrm{NaCl}, \mathrm{pH} 8.0$. The supernatant and the redissolved precipitate fractions were extensively dialysed against 5 mM-sodium phosphate buffer at $\mathrm{pH} 7.4$ and then lyophilized and stored at $-80^{\circ} \mathrm{C}$.

EPF assay. EPF was assayed by the rosette inhibition test, originally described by Bach \& Antoine (1968), and adapted for the assay of EPF by Morton et al. (1974). This test depends on the ability of EPF to enhance the inhibition by antilymphocyte serum of active rosette formation between lymphocytes and heterologous red blood cells (RBC). Modifications of the assay using human male peripheral lymphocytes and sheep RBC have been previously described in detail (Sueoka et al., 1988a, b). In summary, the test sample is incubated with lymphocytes, which are then washed, anti-T cell monoclonal antibody (OKT-11; Ortho Diagnostic Systems, Inc., Raritan, NJ, USA) and complement are added in a microplate well, and the mixture incubated for $30 \mathrm{~min}$ at $37^{\circ} \mathrm{C}$. Then sheep RBC are added to each well, and the microplate is centrifuged at $4^{\circ} \mathrm{C}$. Rosette formation is counted under phase-contrast microscopy after staining the pellet with brilliant cresyl blue. EPF activity is expressed as rosette inhibition titre (RIT). RIT equals $\log _{2}$ of the reciprocal of the highest dilution of antibody in which the number of rosettes formed was less than $75 \%$ of the control value. An RIT of 3 or greater was considered positive for EPF (Rolfe et al., 1984; Sueoka et al., 1988a).

Experiment 1. This experiment was designed to elucidate which organ was the principal source of EPF production and whether at least one of the EPF components was produced in the non-pregnant condition. Perfusions of the ovary + oviduct, ovary alone, and oviduct alone were performed with organs from pregnant, pseudopregnant, and unstimulated rabbits ( 6 for each condition). The perfusate samples were collected and inactivated at $56^{\circ} \mathrm{C}$ for $30 \mathrm{~min}$. Two different types of perfusates were randomly combined together, incubated at $37^{\circ} \mathrm{C}$ for $30 \mathrm{~min}$, and then assayed for EPF.

Experiment 2. Isolation of serum EPF components by ammonium sulphate fractionation has been reported only for serum from EPF-positive pregnant animals (Morton et al., 1980; Clarke et al., 1980). These authors demonstrated that a single serum EPF component does not have EPF activity. The aim of this experiment was to determine whether the serum of pseudopregnant or unstimulated rabbits, which was EPF negative, none the less contained one of the 
EPF components. The fractionated serum precipitate and supernatant collected from pregnant, pseudopregnant, and unstimulated rabbits were incubated together in all possible combinations at $37^{\circ} \mathrm{C}$ for 30 min and then assayed for EPF.

Experiment 3. This experiment was designed to determine the relationship between perfusate and serum components. The hypothesis is that the perfusate components may be similar to or cross-react with the serum components which were previously reported as EPF-A and EPF-B (Morton et al., 1980). Each perfusate component was incubated together with serum precipitate or supernatant fractions from pregnant or pseudopregnant animals at $37^{\circ} \mathrm{C}$ for $30 \mathrm{~min}$ and assayed for EPF ( 6 in each group).

Experiment 4. PAF induces the production or release of EPF components by the ovary and oviduct individually from unstimulated rabbits (Sueoka et al., 1988b). Although neither the perfusate of PAF-exposed oviduct alone nor ovary alone displayed EPF activity, the combined perfusates did contain EPF activity. The aim of this experiment was to investigate whether the PAF-induced EPF-like components from the ovary and oviduct were similar to the serum and perfusate EPF components produced under conditions of pregnancy or pseudopregnancy. Synthetic PAF (1-0hexadecyl-2-0-acetyl-sn-glycero-3-phosphorylcholine; $150 \mu \mathrm{g}$, Bachem Bioscience, Philadelphia, PA, USA) was injected into the tubing of perfusion system just before the entry into the arterial cannula. The perfusate was combined with the same volume of ovary and/or oviduct perfusate from pregnant, pseudopregnant or intact animals, or fractionated serum component from pregnant or pseudopregnant animals ( 6 for each). The combined solutions were incubated at $37^{\circ} \mathrm{C}$ for $30 \mathrm{~min}$ before EPF assay.

Experiment 5. EPF binds to lymphocytes and enhances the ability of anti-lymphocyte serum to inhibit rosette formation (Morton et al., 1976). This experiment was designed to elucidate which EPF components bind directly to lymphocytes. The hypothesis is one component can bind to lymphocytes, but needs the second component to express EPF activity. Serum and perfusate components from pregnant animals were used in all assays. Lymphocytes $\left(2 \times 10^{6}\right)$ were first incubated with $100 \mu \mathrm{l}$ sample of one test component for $30 \mathrm{~min}$ at $37^{\circ} \mathrm{C}$. Lymphocytes were washed 3 times with Hanks balanced salt solution (Whittaker M.A. Bioproducts), and then incubated with the same volume of the second component. After the second incubation the EPF assay was completed by the addition of antibody, complement and RBC. Those component combinations that had no EPF activity were subjected to a third incubation. After the second incubation, lymphocytes were washed again and reincubated with the first test component and the assay for EPF was completed.

Statistical analysis. One way analysis of variance (ANOVA) was used to examine EPF activity of each in serum and/or perfusate component combination. Differences with $P<0.05$ were considered significant.

\section{Results}

\section{Experiment 1: combined ovary and oviduct components}

EPF activity of each perfusate alone was negative (RIT $\leqslant 2$ ). EPF activity was positive (RIT $\geq 3$ ) only in ovary perfusates from pregnant rabbits combined with oviduct-containing perfusates from pseudopregnant or pregnant animals (Table 1). No combination containing perfusates from an unstimulated rabbit contained EPF activity.

Table 1. EPF activity of the combined ovary and oviduct perfusates from unstimulated intact, pseudopregnant, or pregnant rabbits (6/group)

\begin{tabular}{lccc}
\hline & \multicolumn{3}{c}{ Ovary alone } \\
\cline { 2 - 4 } & Unstimulated & Pseudopregnant & Pregnant* \\
\hline Ovary + oviduct & 1.0 & 1.0 & \\
$\quad$ Unstimulated & 1.2 & 1.0 & 1.0 \\
$\quad$ Pseudopregnant & & & 3.3 \\
Oviduct alone & 1.0 & 1.0 & 1.0 \\
$\quad$ Unstimulated & 1.0 & 1.0 & 3.2 \\
Pseudopregnant & 1.0 & 1.0 & 3.3 \\
Pregnant & 1.0 & \\
\hline
\end{tabular}

*RIT $\geq 3$ was significantly different $(P<0.05)$ from RIT $\leq 2$. 


\section{Experiment 2: combined serum components}

Individual serum ammonium sulphate precipitate and supernatant fractions exhibited no EPF activity. Combinations of pregnant serum precipitate with supernatants from pseudopregnant or pregnant serum exhibited EPF activity (Table 2).

Table 2. EPF activity in combinations of serum ammonium sulphate precipitate and supernatant fractions $(n=3)$

\begin{tabular}{lccc}
\hline & \multicolumn{3}{c}{ Precipitate } \\
\cline { 2 - 4 } Supernatant & Unstimulated & Pseudopregnant & Pregnant* \\
\hline Unstimulated & 1.3 & $1 \cdot 3$ & $1 \cdot 3$ \\
Pseudopregnant & 1.3 & 1.7 & $2 \cdot 3$ \\
Pregnant & 1.7 & 1.3 & 3.3 \\
\hline
\end{tabular}

*RIT $\geq 3$ was significantly different $(P<0.05)$ from RIT $\leq 2$.

\section{Experiment 3: combination of perfusate and serum components}

The serum supernatant fractions from pregnant and pseudopregnant animals contained EPF activity only when combined with perfusates from the pregnant ovary (Table 3 ). Pregnant serum precipitate fractions produced EPF activity when combined with perfusates from pseudopregnant or pregnant ovary + oviduct or oviduct alone. Serum precipitate fractions of pseudopregnant animals showed no EPF activity in any combination with perfusate.

Experiment 4: PAF-induced perfusate combined with serum or perfusate EPF components from pregnant or pseudopregnant animals

The perfusate of the PAF-exposed oviduct displayed EPF activity only when combined with the perfusate of pregnant ovary (Table 4). EPF-like activity was present in the perfusate of the PAFexposed ovary when combined with perfusates containing the oviduct from a pregnant or pseudopregnant animal. The pattern of EPF-like activity in these combinations was similar to that seen in pregnant serum fractions (Table 3).

These same experiments were repeated with serum fractions. Perfusates of PAF-exposed ovary and oviduct had positive EPF-like activity when combined with pregnant serum supernatant and precipitate fractions respectively (Table 5). However, perfusates of PAF-exposed oviduct did not express EPF-like activity when combined with pseudopregnant serum fractions. Perfusates of PAF-exposed ovaries had EPF-like activity when combined with the serum supernatant fraction from pseudopregnant animals.

\section{Experiment 5: lymphocyte binding of components}

Supernatant and precipitate fractions of pregnant serum were separately incubated with lymphocytes (Table 6). The order of incubation proved to be extremely important. When the first incubation was with the supernatant, the lymphocytes exhibited EPF activity. Lymphocytes incubated first with the precipitate fraction did not exhibit EPF activity until reincubated with precipitate after incubation with supernatant.

Similar results were obtained when lymphocytes were incubated with oviduct and ovary perfusates: EPF activity was positive when the first incubation was with the oviduct perfusate, and negative when the first incubation was with ovary. Even though its opposite order of incubation expressed no EPF activity, the second incubation with ovary perfusate produced EPF activity. 

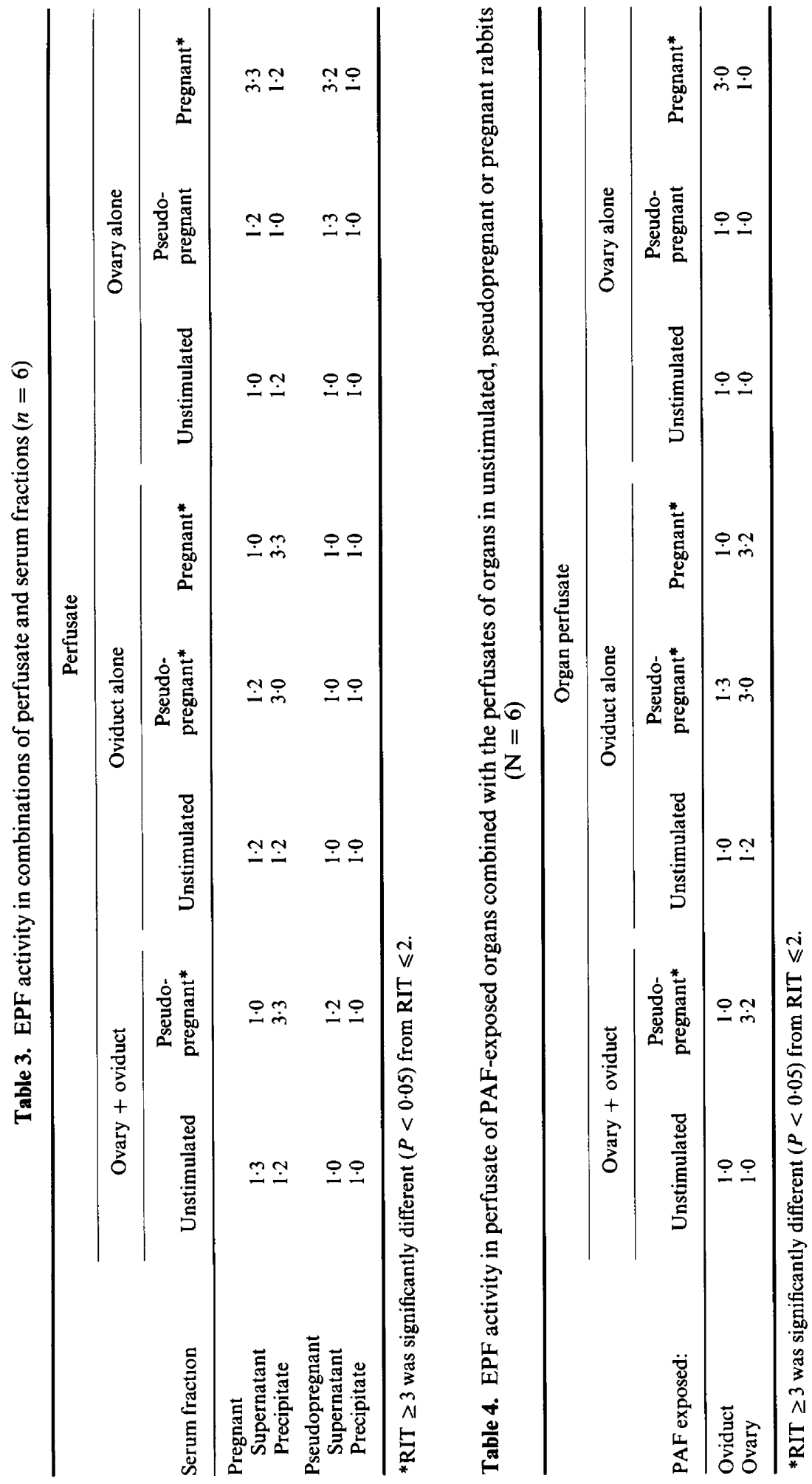
Table 5. EPF activity in perfusates of PAF-exposed organs combined with serum fractions from pseudopregnant or pregnant rabbits $(\mathrm{N}=6)$

\begin{tabular}{lccccc}
\hline & \multicolumn{4}{c}{ Serum fraction } \\
\cline { 2 - 3 } & \multicolumn{2}{c}{ Pregnant } & & \multicolumn{2}{c}{ Pseudopregnant } \\
\cline { 2 - 3 } \cline { 5 - 6 } PAF-exposed: & Supernatant* & Precipitate* & & Supernatant* & Precipitate \\
\hline Oviduct & $1 \cdot 2$ & 3.0 & & 1.0 & 1.0 \\
Ovary & 3.0 & 1.0 & & 3.0 & 1.3 \\
\hline
\end{tabular}

*RIT $\geq 3$ was significantly different $(P<0 \cdot 05)$ from RIT $\leq 2$.

Table 6. EPF activity in lymphocytes incubated with serum fractions or perfusate fractions from pregnant rabbits $(\mathrm{N}=6)$

\begin{tabular}{|c|c|}
\hline & $\begin{array}{c}\mathrm{EPF} \\
\text { activity* }\end{array}$ \\
\hline \multicolumn{2}{|l|}{ Serum fraction } \\
\hline Supernatant $\rightarrow$ precipitate & $3 \cdot 3$ \\
\hline Precipitate $\rightarrow$ supernatant & $1 \cdot 2$ \\
\hline $\begin{array}{l}\text { Precipitate } \rightarrow \text { supernatant } \rightarrow \\
\text { precipitate }\end{array}$ & $3 \cdot 5$ \\
\hline \multicolumn{2}{|l|}{ Perfusate } \\
\hline Oviduct $\rightarrow$ ovary & $3 \cdot 5$ \\
\hline Ovary $\rightarrow$ oviduct & 1.0 \\
\hline Ovary $\rightarrow$ oviduct $\rightarrow$ ovary & $3 \cdot 2$ \\
\hline
\end{tabular}

\section{Discussion}

EPF components have been previously identified in serum and organ-culture media (Morton et al., 1980; Clarke et al., 1980). However, our present results demonstrate the production of EPF components directly by collecting the organ perfusate. EPF components are produced independently by the ovary and oviduct (Tables 1 and 4). The ovary component is produced only in pregnancy, but the oviduct component is produced in pseudopregnancy to the same extent as in pregnancy. This indicates that the oviduct component is triggered along with ovulation and does not require fertilization. As the component production was only determined $24 \mathrm{~h}$ after hCG exposure, the exact onset of production is not yet clear. It is possible that some of the inflammatory mechanisms that are active during the process of ovulation (Espey, 1980) may induce production of the EPF oviduct component. Production of the oviduct component may require luteinization or the direct interaction of the ovum or its product with the oviduct.

Individual rabbit serum components had no EPF activity, as reported for other species (Clarke et al., 1980; Cavanagh et al., 1982). Our results demonstrate that fertilization is necessary for the production of the serum precipitate component. However, like the oviduct component, the serum supernatant component is released at the time of ovulation in the absence of fertilization. Serum and perfusate components can be combined to yield EPF activity and, together with the similar patterns of production, suggests that the oviduct component is similar or identical to the serum supernatant component and that the ovary component is similar or identical to the serum precipitate component. It is most likely that the individual components are produced by the ovary and oviduct and enter the serum in which EPF activity is displayed. 
PAF appeared to induce the production of both ovary and oviduct components. This pattern is similar to the pattern of EPF production in pregnancy (i.e. both ovary and oviduct components). While PAF may well be the factor inducing EPF in pregnancy, another factor must stimulate the production of the oviduct component in pseudopregnancy.

The serum lymphocyte-binding component, EPF-A, has been previously demonstrated in the mouse (Morton et al., 1980; Clark et al., 1980). The present results identify the organ producing these components. The oviduct component appears to bind directly to lymphocytes. The ovary component does not bind to lymphocytes, but is able to interact directly with the other EPF component after it has bound to lymphocytes. The oviduct component is released into the circulation and may bind to lymphocytes even in the absence of fertilization.

Overall, the results demonstrate that EPF contains two components, one produced by the ovary and the other by the oviduct. Pregnancy and PAF can stimulate production of both components while only the oviduct component is stimulated during pseudopregnancy.

We thank Dr Norman H. Dubin for valuable suggestions; R. B. Ghodgaonkar for expert technical assistance; and Ms Fran Karas for assistance in preparation of the manuscript. This work was supported by the Lalor and Mitchell and Lillian Duberstein Foundations.

\section{References}

Bach, J.F. \& Antoine, B. (1968) In vitro detection of immunosuppressive activity of anti-lymphocyte sera. Nature, Lond. 217, 658-659.

Cavanagh, A.C., Morton, H., Rolfe, B.E. \& Gidley-Baird, A.A. (1982) Ovum factor: a first signal of pregnancy? Am. J. Reprod. Immunol. 2, 97-101.

Clarke, F.M., Morton, H., Rolfe, B.E. \& Clunie, G.J.A. (1980) Partial characterization of early pregnancy factor in the sheep. J. Reprod. Immunol. 2, 151-162.

Dharmarajan, A.M., Yoshimura, Y., Sueoka, K., Atlas, S.J., Dubin, N.H., Ewing, L.L., Zirkin, B. \& Wallach, E.E. (1988) Progesterone secretion by corpora lutea of the isolated perfused rabbit ovary during pseudopregnancy. Biol. Reprod. 38, 1137-1183.

Espey, L.L. (1980) Ovulation as an inflammatory reaction-a hypothesis. Biol. Reprod. 22, 73-106.

Kobayashi, Y., Wright, K.H., Santulli, R. \& Wallach, E.E. (1981) Ovulation and ovum maturation in the rabbit ovary perfused in vitro. Biol. Reprod. 24, 483-490.

Lambertsen, C.J., Jr, Greenbaum, D.F., Wright, K.H. \& Wallach, E.E. (1976) In vitro studies of ovulation in the perfused rabbit ovary. Fert. Steril. 27, 178-187.

Morton, H., Hegh, V. \& Clunie, G.J.A. (1974) Immunosuppression detected in pregnant mice by rosette inhibition test. Nature, Lond. 249, 459-460.

Morton, H., Hegh, V. \& Clunie, G.J.A. (1976) Studies of the rosette inhibition test in pregnant mice: evidence of immunosuppression? Proc. R. Soc. Lond. B 193, 413-419.

Morton, H., Rolfe, B.E., McNeill, L., Clarke, F.M. \& Clunie, G.J.A. (1980) Early pregnancy factor: tissues involved in its production in the mouse. J. Reprod. Immunol. 2, 73-82.
O'Neill, C. (1985) Thrombocytopenia is an initial maternal response to fertilization in mice. J. Reprod. Fert. 73, 559-566.

O'Neill, C., Gidley-Baird, A.A., Pike, I.L., Porter, R.N., Sinosich, M.J. \& Saunders, D.M. (1985) Maternal blood platelet physiology and luteal-phase endocrinology as a means of monitoring pre- and postimplantation embryo viability following in vitro fertilization. J. in Vitro Fert. Embryo Transfer 2, 87-93.

Orozco, C., Perkins, T. \& Clarke, F.M. (1986) Plateletactivating factor induces the expression of early pregnancy factor activity in female mice. J. Reprod. Fert. 78, $549-555$.

Rolfe, B.E., Morton, H. \& Clarke, F.M. (1983) Early pregnancy factor is an immunosuppressive contaminant of commercial preparations of human chorionic gonadotropin. Clin. exp. Immunol. 51, 45-52.

Rolfe, B.E., Cavanagh, A.C., Forde, C., Bastin, F., Chen, C. \& Morton, H. (1984) Modified rosette inhibition test with mouse lymphocytes for detection of early pregnancy factor in human pregnancy serum. $J$. Immunol. Meth. 70, 1-11.

Sueoka, K., Dharmarajan, A.M., Michael, E., Atlas, S.J. \& Wallach, E.E. (1988a) Detection of early pregnancy factor (EPF) using the rabbit ovary and oviduct perfused in vitro. J. Reprod. Fert. 84, 325-331.

Sueoka, K., Dharmarajan, A.M., Miyazaki, T., Atlas, S.J. \& Wallach, E.E. (1988b) Platelet activating factor-induced early pregnancy factor activity from the perfused rabbit ovary and oviduct. Am. J. Obstet. Gynecol. 159, 1580-1584.

Received 4 October 1988 